Louisiana State University

LSU Digital Commons

8-9-2016

\title{
Ammonia Binding in the Second Coordination Sphere of the Oxygen-Evolving Complex of Photosystem II
}

\author{
David J. Vinyard \\ Yale University \\ Mikhail Askerka \\ Yale University \\ Richard J. Debus \\ University of California, Riverside \\ Victor S. Batista \\ Yale University \\ Gary W. Brudvig \\ Yale University
}

Follow this and additional works at: https://digitalcommons.Isu.edu/biosci_pubs

\section{Recommended Citation}

Vinyard, D., Askerka, M., Debus, R., Batista, V., \& Brudvig, G. (2016). Ammonia Binding in the Second Coordination Sphere of the Oxygen-Evolving Complex of Photosystem II. Biochemistry, 55 (31), 4432-4436. https://doi.org/10.1021/acs.biochem.6b00543 


\title{
Ammonia Binding in the Second Coordination Sphere of the Oxygen-Evolving Complex of Photosystem II
}

\author{
David J. Vinyard, ${ }^{\dagger}$ Mikhail Askerka, ${ }^{\dagger}$ Richard J. Debus, ${ }^{\ddagger}$ Victor S. Batista, ${ }^{\dagger}$ and Gary W. Brudvig* ${ }^{*}{ }^{\dagger}$
}

${ }^{\dagger}$ Department of Chemistry, Yale University, New Haven, Connecticut 06520-8107, United States

${ }^{\ddagger}$ Department of Biochemistry, University of California, Riverside, California 92521, United States

\section{Supporting Information}

ABSTRACT: Ammonia binds to two sites in the oxygenevolving complex (OEC) of Photosystem II (PSII). The first is as a terminal ligand to $\mathrm{Mn}$ in the $\mathrm{S}_{2}$ state, and the second is at a site outside the OEC that is competitive with chloride. Binding of ammonia in this latter secondary site results in the $S_{2}$ state $S=5 / 2$ spin isomer being favored over the $S=1 / 2$ spin isomer. Using electron paramagnetic resonance spectroscopy, we find that ammonia binds to the secondary site in wild-type Synechocystis sp. PCC 6803 PSII, but not in D2-K317A

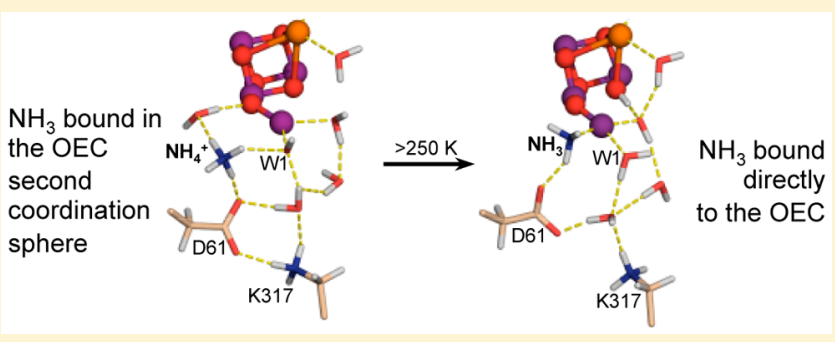
mutated PSII that does not bind chloride. By combining these results with quantum mechanics/molecular mechanics calculations, we propose that ammonia binds in the secondary site in competition with D1-D61 as a hydrogen bond acceptor to the OEC terminal water ligand, W1. Implications for the mechanism of ammonia binding via its primary site directly to $\mathrm{Mn} 4$ in the OEC are discussed.

xygenic photosynthesis in cyanobacteria, algae, and plants converts solar energy to chemical energy by oxidizing water to molecular oxygen $\left(\mathrm{O}_{2}\right)$ in the Photosystem II (PSII) reaction center. The protons stripped from water contribute to the proton motive force across the thylakoid membrane, and the electrons are used to reduce plastoquinone to plastoquinol. ${ }^{1}$ The active site of water oxidation is the oxygen-evolving complex [OEC (Figure 1)], which is a $\mathrm{Mn}_{4} \mathrm{CaO}_{5}$ inorganic cluster ligated

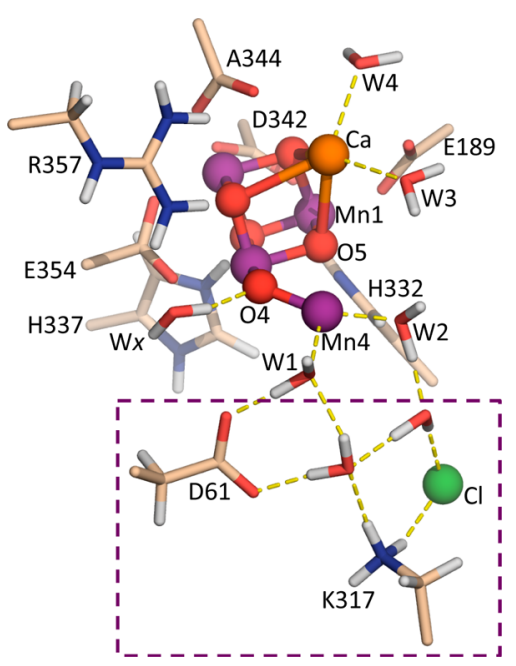

Figure 1. QM/MM-optimized structure of the $S_{2}$ state $S=5 / 2$ spin isomer of the PSII OEC. ${ }^{10}$ Ammonia binds outside the OEC at a site competitive with chloride in an area hypothesized to be within the dashed square. by amino acid residues and water molecules. ${ }^{2}$ The OEC cycles through four metastable redox intermediates $\left(S_{n}\right.$ states, where $n$ $=0-3$ ) during its catalytic cycle as described by Kok and coworkers. ${ }^{3}$ The $\mathrm{S}_{3}$ state is oxidized to a proposed transient $\mathrm{S}_{4}$ intermediate that spontaneously releases $\mathrm{O}_{2}$, binds $\mathrm{H}_{2} \mathrm{O}$, and reforms $\mathrm{S}_{0}$. X-ray crystallography, X-ray absorption and emission spectroscopies, EPR spectroscopy, and computational modeling have revealed key features of the OEC structure in states $S_{0}-S_{3}$ (reviewed in ref 4). However, the nature of $\mathrm{S}_{4}$ and, therefore, the chemical mechanism of $\mathrm{O}-\mathrm{O}$ bond formation have not been experimentally characterized.

The precise binding sites of the two substrate waters that give rise to $\mathrm{O}_{2}$ are not known. ${ }^{4}$ An oxo-oxyl radical coupling mechanism for $\mathrm{O}-\mathrm{O}$ bond formation has been proposed with the substrate waters bound as a terminal oxyl ligand to a $\mathrm{Mn}^{4+}$ and a $\mu$-oxo bridge in the $S_{4}$ state. ${ }^{5,6}$ Alternatively, a water nucleophile attack mechanism has been proposed for which the substrate waters are bound as a terminal oxo ligand to a $\mathrm{Mn}^{5+}$ and a terminal water ligand to $\mathrm{Ca}^{2+} \cdot{ }^{7-9}$ Therefore, identifying the sites of substrate water binding is a strategy for understanding the chemical mechanism of photosynthetic water oxidation.

Ammonia is an electronic and structural analogue of water and binds in two distinct sites in PSII. ${ }^{11}$ Upon formation of the $S_{2}$ state, ammonia was recently proposed to bind as an additional ${ }^{10}$ terminal ligand to $\mathrm{Mn} 4^{12,13}$ (in the $S=5 / 2$ spin isomer with $\mathrm{Mn}$ oxidation states IV, IV, IV, and III for Mn1-Mn4, respectively), thus completing the octahedral coordination sphere ${ }^{10}$ and

Received: May 29, 2016

Revised: July 18, 2016

Published: July 19, 2016 
stabilizing the complex ${ }^{14}$ in the $S=1 / 2$ spin isomer (with $\mathrm{Mn}$ oxidation states III, IV, IV, and IV for Mn1-Mn4, respectively). ${ }^{15}$ Previously, we proposed that ammonia binding in the $S_{2}$ state is analogous to water binding during the $S_{2}$ to $S_{3}$ transition. ${ }^{10}$ Quantum mechanics/molecular mechanics (QM) $\mathrm{MM}$ ) studies of ammonia binding to the $S_{2}$ state suggest that previously bound terminal waters (W1 and W2) move in a "carousel" around Mn4. ${ }^{10}$ This mechanism, a similar version of which was later proposed by Pantazis and co-workers, ${ }^{16}$ helps to explain how water is directed from hydrogen bonding networks within PSII $^{17}$ to the OEC and further activated for $\mathrm{O}_{2}$ production.

Ammonia also binds outside the OEC at a previously unresolved site that is competitive with chloride. ${ }^{18,19}$ A highaffinity chloride is bound approximately $7 \AA$ from the dangler Mn in the $\mathrm{OEC}^{2}$ as shown in Figure 1. When dark-adapted PSII membranes from spinach are illuminated at $200 \mathrm{~K}$ to advance the OEC from the $S_{1}$ state to the $S_{2}$ state in the presence of ammonia, the intensity of the $g=4.1 \mathrm{~S}_{2}$ state EPR signal (corresponding to the $S=5 / 2$ spin isomer) is inversely proportional to chloride concentration. ${ }^{19}$ While this secondary ammonia-binding site and chloride are clearly competitive, ${ }^{18}$ it is not obvious that an amine free base and a halide would occupy the same site in the protein matrix.

Previously, we showed that chloride binding requires the presence of D2-K317 in Synechocystis sp. PCC $6803 .{ }^{20}$ In wildtype (WT) PSII, chloride prevents D2-K317 from forming a salt bridge with D1-D61 ${ }^{21}$ and likely regulates the hydrogen bonding network within the broad channel ${ }^{17}$ to promote efficient proton transfer away from the OEC. Notably, neither WT cyanobacterial PSII nor PSII from the D2-K317A mutant exhibits a $g=4.1 \mathrm{EPR}$ signal in the $S_{2}$ state. $^{20,22}$

Herein, we show that ammonia binding in the secondary binding site is inhibited in D2-K317A PSII. The combination of this observation and QM/MM modeling suggests that ammonia replaces D1-D61 as a hydrogen bond acceptor to $\mathrm{W} 1$ in the second coordination sphere of the OEC. This proposed binding site is distinct from, but intimately connected to, the chloridebinding site.

\section{MATERIALS AND METHODS}

PSII core complexes were purified from His-tagged $\mathrm{CP} 47^{23}$ "wild-type" and the D2-K317A mutant of Synechocystis sp. PCC 6803 as previously described. ${ }^{20}$ Briefly, cells were grown mixotrophically with $5 \mathrm{mM}$ glucose and warm white fluorescent lighting $\left(80 \mu \mathrm{E} \mathrm{m}^{-2} \mathrm{~s}^{-1}\right)$ and bubbled with $5 \% \mathrm{CO}_{2}$ in air. Cell lysis was performed using silica/zirconia beads in a chilled Beadbeater, and thylakoid membranes were isolated by centrifugation. Thylakoids were resuspended to a chlorophyll concentration of $1 \mathrm{mg} \mathrm{mL}^{-1}$ and solubilized with $1 \% n$-dodecyl $\beta$-D-maltoside (DM) for $20 \mathrm{~min}$. His-tagged PSII core complexes were purified using Ni-NTA resin and eluted in buffer containing $50 \mathrm{mM}$ L-histidine, $50 \mathrm{mM}$ MES (pH 6.0), $20 \mathrm{mM} \mathrm{CaCl}_{2}, 5 \mathrm{mM}$ $\mathrm{MgCl}_{2}, 10 \%(\mathrm{v} / \mathrm{v})$ glycerol, $1.2 \mathrm{M}$ betaine, and $0.03 \% \mathrm{DM}$. Following the addition of $1 \mathrm{mM}$ EDTA, PSII core complexes were concentrated using centrifugal filters with a $100000 \mathrm{kDa}$ cutoff and stored at $77 \mathrm{~K}$.

A small volume of whole cells from each batch was reserved, and genomic DNA was purified. Fragments containing the $p s b A 2$ and $p s b D 1$ genes in their entirety were amplified via polymerase chain reaction using primers previously designed ${ }^{24,25}$ and sequenced to verify the integrity of each strain. Light-saturated $\mathrm{O}_{2}$ evolution activities of the PSII core complex samples were
2500-3000 $\mu \mathrm{mol}$ of $\mathrm{O}_{2}(\mathrm{mg} \text { of Chl })^{-1} \mathrm{~h}^{-1}$ for WT and 1500$1800 \mu \mathrm{mol}$ of $\mathrm{O}_{2}(\mathrm{mg} \text { of } \mathrm{Chl})^{-1} \mathrm{~h}^{-1}$ for D2-K317A in the presence of $0.25 \mathrm{mM} 2,5$-dichloro-p-benzoquinone and $1 \mathrm{mM}$ potassium ferricyanide.

Ammonia binding was studied in a buffer containing $1 \mathrm{M}$ sucrose, $45 \mathrm{mM}$ HEPES ( $\mathrm{pH} 7.5$ ), $11 \mathrm{mM} \mathrm{Ca}(\mathrm{OH})_{2}, 0.5 \mathrm{mM}$ EDTA, and $0.03 \%$ DM. Additional experiments were performed in which $1 \mathrm{M}$ sucrose was replaced with $1.2 \mathrm{M}$ betaine or $25 \%$ (v/ v) glycerol. For buffer exchange, PSII core complexes were diluted by approximately 10-fold and concentrated using centrifugal filters. This process was repeated 10-14 times. EPR samples were prepared by adding $100 \mathrm{mM} \mathrm{NH}_{4} \mathrm{Cl}$ (from a $2 \mathrm{M}$ stock) to PSII core complexes at approximately $1.5 \mathrm{mg}$ of $\mathrm{Chl}$ $\mathrm{mL}^{-1}\left(\sim 48 \mu \mathrm{M}\right.$ PSII and $\left.1.8 \mathrm{mM} \mathrm{NH}_{3}\right)$. The $\mathrm{S}_{2}$ state was generated by illuminating dark-adapted PSII samples at $200 \mathrm{~K}^{26}$ Annealed samples were warmed to $273 \mathrm{~K}$ in an ice water bath for approximately $30 \mathrm{~s}$ and then frozen in liquid nitrogen.

EPR spectra were recorded using a Bruker ELEXSYS E500 spectrometer equipped with a SHQ cavity and an Oxford ESR900 helium flow cryostat at 6-7 K. Instrument parameters were as follows: microwave frequency, $9.39 \mathrm{GHz}$; microwave power, 2-5 mW; modulation frequency, $100 \mathrm{kHz}$; modulation amplitude, $19.5 \mathrm{G}$; sweep time, $84 \mathrm{~s}$; conversion time, $41 \mathrm{~ms}$; time constant, $82 \mathrm{~ms}$. Four scans were averaged for each experiment.

$\mathrm{QM} / \mathrm{MM}$ calculations were performed as previously described $^{10,27-29}$ using the B3LYP functional ${ }^{30,31}$ with the

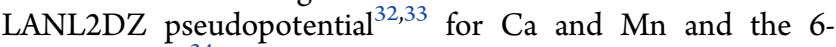
$31 \mathrm{G}^{*}$ basis set ${ }^{34}$ for all other atoms. The AMBER force field was used for all MM layer atoms. ${ }^{35}$ The $20111.9 \AA$ A structure was used as an initial approximation for the $\mathrm{S}$ state models. ${ }^{2}$ The models included all amino acid residues within $15 \AA$ of the OEC, as well as the water molecules and chloride cofactors. The capping $\mathrm{ACE} / \mathrm{NME}$ groups were added to the $\mathrm{C} / \mathrm{N}$ termini at the chain breaks. Two sodium atoms were added to the model to compensate for the excess negative charge of the overall $15 \AA$ cut. A neutral $\mathrm{NH}_{3}$ molecule was added to investigate the secondary ammonia-binding motif. The total model included 2492 atoms. The QM layer contained 131 atoms, including D1-A344, D1E189, CP43-E354, D1-H332, D1-D170, D1-E333, D1-D342, D1-H337, CP43-R357, D1-D61, D2-K317, chloride (except in the secondary ammonia structure), and all waters in the vicinity of these residues.

\section{RESULTS AND DISCUSSION}

In spinach PSII membranes, the relative populations of the $S_{2}$ state $S=1 / 2$ and $S=5 / 2$ spin isomers are sensitive to the choice of cryoprotectant. $^{22,36}$ The typical elution buffer for Synechocystis PSII core complexes purified by Ni-affinity chromatography includes both $10 \%(\mathrm{v} / \mathrm{v})$ glycerol and $1.2 \mathrm{M}$ betaine, which would favor formation of the $S=1 / 2$ spin isomer based on results with spinach PSII membranes. ${ }^{36}$ To test the effect of cyroprotectant on the equilibrium between the $S_{2}$ state spin isomers in cyanobacteria, Synechocystis PSII core complexes were rigorously buffer exchanged into $1 \mathrm{M}$ sucrose, $45 \mathrm{mM}$ HEPES ( $\mathrm{pH} 7.5), 11 \mathrm{mM} \mathrm{Ca}(\mathrm{OH})_{2}, 0.5 \mathrm{mM}$ EDTA, and 0.03\% DM (see Materials and Methods). As shown in Figure 2, only the $S_{2}$ state multiline $(g=2)$ EPR signal is observed in WT and K317A PSII in all cases.

Then, $100 \mathrm{mM} \mathrm{NH} \mathrm{ml}_{4} \mathrm{Cl}$ was added to samples containing sucrose as a cryoprotectant, and the samples were illuminated at $200 \mathrm{~K}$. As shown in Figure 3 (spectrum A), a broad $g=4.1 \mathrm{EPR}$ signal is observed in WT PSII corresponding to the $S_{2}$ state $S=$ 


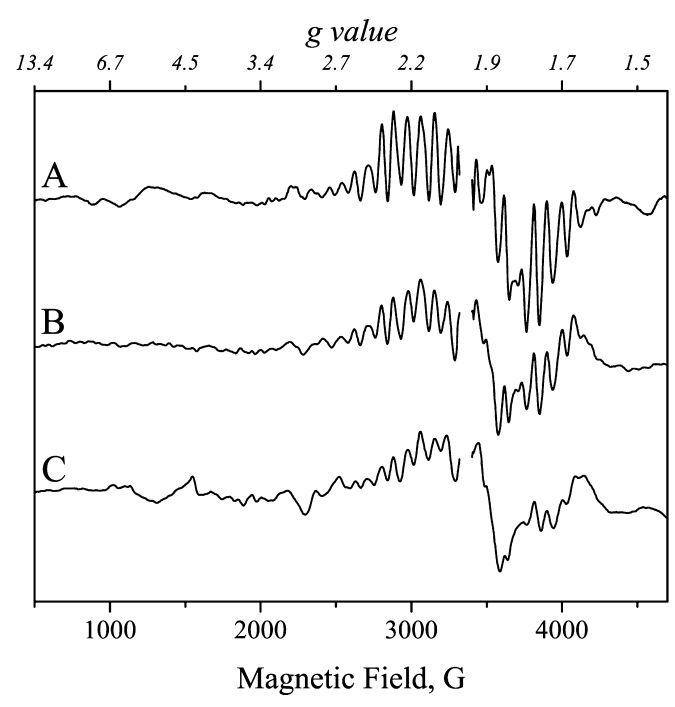

Figure 2. $\mathrm{S}_{2}$ state light-minus-dark EPR spectra of (A) WT PSII core complexes in elution buffer $[1.2 \mathrm{M}$ betaine and $10 \%(\mathrm{v} / \mathrm{v})$ glycerol $(\mathrm{pH}$ 6.0)], (B) WT PSII core complexes in $1 \mathrm{M}$ sucrose ( $\mathrm{pH} 7.5$ ), and (C) K317A PSII core complexes in $1 \mathrm{M}$ sucrose $(\mathrm{pH} 7.5)$. Spectra were recorded at $6.2-6.4 \mathrm{~K}$ using a microwave power of $2 \mathrm{~mW}$. Unsubtracted spectra are shown in Figure $S 1$ of the Supporting Information.

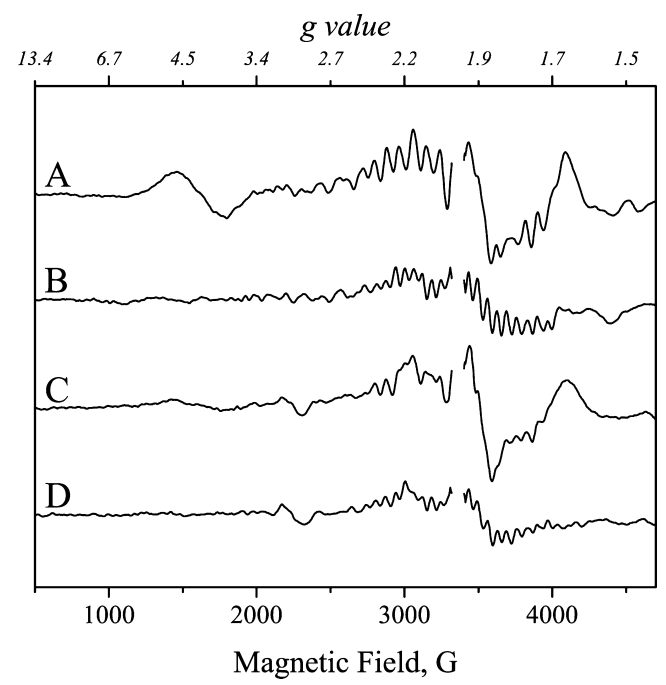

Figure 3. $\mathrm{S}_{2}$ state light-minus-dark EPR spectra in the presence of 100 $\mathrm{mM} \mathrm{NH} \mathrm{Nl}_{4} \mathrm{Cl}(\mathrm{pH}$ 7.5). WT PSII core complexes illuminated at $200 \mathrm{~K}$ (A) and then annealed to $273 \mathrm{~K}(\mathrm{~B})$. K317A PSII core complexes illuminated at $200 \mathrm{~K}$ (C) and then annealed to $273 \mathrm{~K}$ (D). Spectra were recorded at $6.2-6.4 \mathrm{~K}$ using a microwave power of $2 \mathrm{~mW}$. Unsubtracted spectra are shown in Figures S3 and S4 of the Supporting Information.

$5 / 2$ spin isomer. The appearance of this signal is independent of cryoprotectant choice (see Figure S2 of the Supporting Information). When the sample is annealed to $273 \mathrm{~K}$, the $g=$ 4.1 signal is lost and the $g=2$ multiline signal is altered (Figure 3, spectrum B). This behavior is analogous to that found in previous studies of spinach PSII membranes: ammonia binding in the secondary site (outside the OEC) induces a $g=4.1 \mathrm{EPR}$ signal in the $S_{2}$ state formed by $200 \mathrm{~K}$ illumination, and ammonia binding in the primary site (directly to the OEC) causes an alteration of the $\mathrm{S}_{2}$ state $g=2 \mathrm{EPR}$ signal upon annealing. ${ }^{15}$

For K317A PSII, only a very weak $g=4.1 \mathrm{EPR}$ signal is observed upon $200 \mathrm{~K}$ illumination (Figure 3, spectrum C). When the sample is annealed at $273 \mathrm{~K}$, an altered $\mathrm{S}_{2}$ state $g=2$ multiline spectrum is observed that closely matches that of the WT (Figure 3 , spectrum D). The absence of a clear $S_{2}$ state $g=4.1 \mathrm{EPR}$ spectrum in K317A PSII suggests that ammonia does not bind to the secondary site, while ammonia is still capable of binding to the primary site.

The observation of a significant decrease in the magnitude of the $\mathrm{S}_{2}$ state $g=4.1 \mathrm{EPR}$ signal in $\mathrm{K} 317 \mathrm{~A}$ compared to that in WT PSII in the presence of $100 \mathrm{mM} \mathrm{NH}_{4} \mathrm{Cl}$ led to the ammoniabinding model shown in Figure 4. While ammonia binding in the second coordination sphere of the OEC is competitive with that of chloride, ${ }^{18,19}$ we hypothesized that it does not bind at the same site. Instead, the occupancy of the high-affinity chloride site indirectly affects ammonia binding. As shown in Figure 4B, when chloride is depleted, D61 moves away from W1 to form an ion pair with $\mathrm{K} 317 .^{21}$ Ammonia can then bind as a hydrogen bond acceptor to W1. In K317A PSII (Figure 4C), chloride does not bind $^{20}$ and D61 is unable to form a salt bridge with K317. Therefore, D61 remains a strong hydrogen bond acceptor to W1 and blocks ammonia from binding.

To test this hypothesis, we used QM/MM calculations to determine an energy-minimized structure of ammonia bound in the proposed site (Figure 5A, a PDB file is available in the Supporting Information). This structure represents the $\mathrm{S}_{2}$ state $S$ $=5 / 2$ spin isomer (oxidation states IV, IV, IV, and III) $)^{10,37}$ and was prepared by removing chloride and adding ammonia (as neutral $\mathrm{NH}_{3}$ ) near W1. Intriguingly, calculations show that the terminal aqua ligand $\mathrm{W} 1$ is deprotonated by ammonia to form a terminal hydroxo ligand and ammonium. This finding is consistent with both biochemical studies that suggest the secondary site binding is proportional to the concentration of ammonia $^{11,18}$ and FTIR studies that identified ammonium interacting with one or more carboxylate groups near the OEC. ${ }^{38}$

The secondary ammonia-binding site reported here is adjacent to our previously reported primary ammonia-binding site (Figure 5B). ${ }^{10}$ As discussed above, dark-adapted WT PSII samples illuminated at $200 \mathrm{~K}$ in the presence of $\mathrm{NH}_{4} \mathrm{Cl}$ exhibit $g$ $=4.1\left(S=5 / 2 S_{2}\right.$ state spin isomer, ammonia bound in the secondary site $)$ and $g=2\left(S=1 / 2 S_{2}\right.$ state spin isomer, ammonia not bound in the secondary site) EPR signals. When the sample is annealed in darkness at $>250 \mathrm{~K}$, the $\mathrm{S}_{2}$ state $g=4.1 \mathrm{EPR}$ signal is lost and the $S_{2}$ state $g=2$ signal is altered, indicating that ammonia has bound directly to the OEC. In our models, ammonia binds to the secondary site outside the OEC in some fraction of centers in the $S_{1}$ intermediate and is protonated to form ammonium. Those sites that have ammonia/ammonium bound advance to the $S=5 / 2$ spin isomer of the $S_{2}$ state upon illumination at $200 \mathrm{~K}$. When the temperature is increased to $>250 \mathrm{~K}$, ammonium migrates to form a direct ligand to the dangler Mn4 (Figure 5), leading to additional $8.7 \mathrm{kcal} / \mathrm{mol}$ stabilization (see Figure S5). This change involves the transfer of a proton from ammonium to $\mathrm{W} 1$ and the transfer of a proton from W2 to O5. ${ }^{10}$ The Mn oxidation states of the OEC change from IV, IV, IV, and III $(S=5 / 2)$ to III, IV, IV, and IV $(S=1 / 2) .{ }^{10}$

The binding of ammonia in the secondary site is not a requirement of ammonia binding in the primary site, because the latter is not chloride-dependent. ${ }^{18,19}$ Instead, we propose that the reaction shown in Figure 5 is the most efficient (lowest-barrier) route for ammonia to bind to the primary site. Because the annealing step involves an elevated temperature and is relatively slow (>10 s), ammonia is able to move through the extensive hydrogen bonded networks connecting the OEC to the lumen ${ }^{17}$ and bind to the OEC. For the case in which ammonia is bound in the secondary site or the case in which it must enter via a channel, 

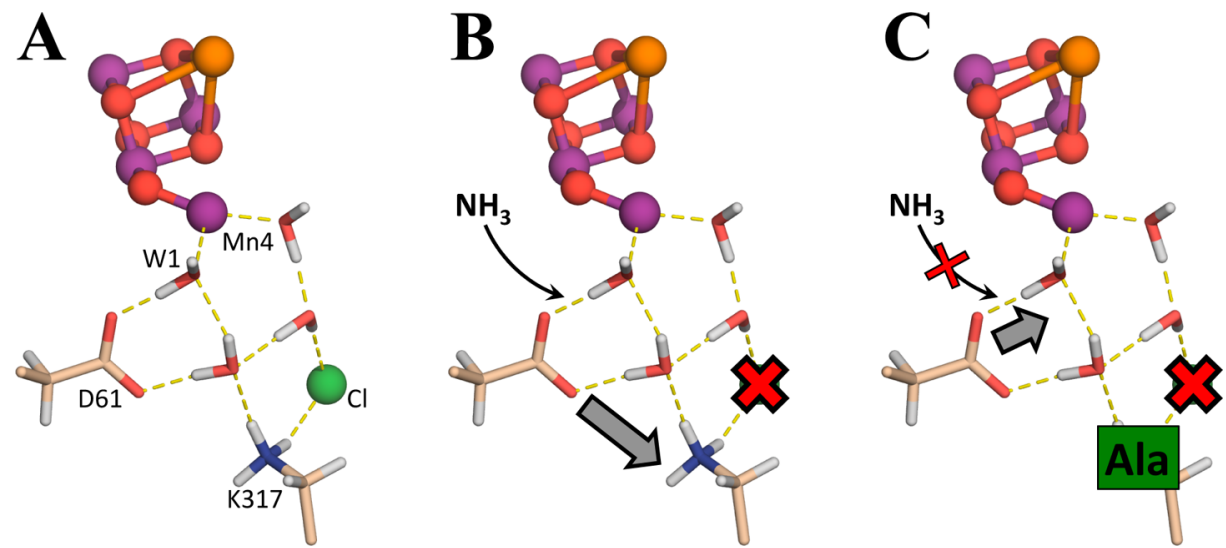

Figure 4. Proposed model of chloride-competitive ammonia binding outside the OEC. (A) Native structure of the $\mathrm{S}_{2}$ state $S={ }^{5} / 2$ spin isomer. ${ }^{10}$ (B) Ammonia competes with D61 as a hydrogen bond acceptor to W1. Upon chloride depletion, D61 moves away from W1 due to formation of a salt bridge with $\mathrm{K} 317 .^{20}$ (C) In K317A PSII, chloride does not bind. D61 remains a strong hydrogen bond acceptor to W1, and ammonia is unable to bind.

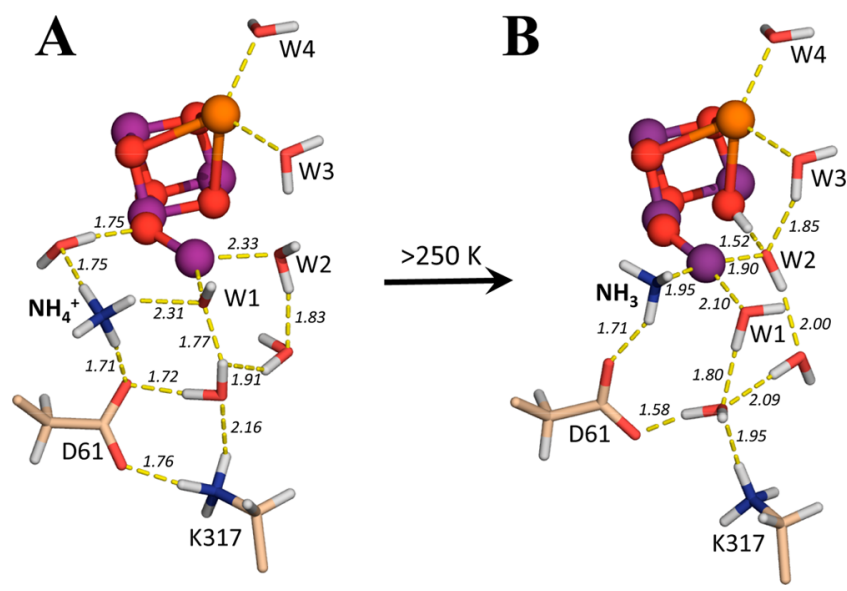

Figure 5. (A) QM/MM-optimized structure of ammonia bound in the secondary site in the $\mathrm{S}_{2}$ state intermediate of the $\operatorname{OEC}(S=5 / 2$ with $\mathrm{Mn}$ oxidation states IV, IV, IV, and III). Above approximately $250 \mathrm{~K}$, ammonia migrates to the primary binding site (B) $(S=1 / 2$ with $\mathrm{Mn}$ oxidation states III, IV, IV, and IV).$^{10}$ See Figure S5 for additional information about primary/secondary site energetics. Selected distances are shown in angstroms.

its binding directly to the OEC is thermodynamically driven by the $>120 \mathrm{mV}\left(>2.7 \mathrm{kcal} \mathrm{mol}^{-1}\right)$ stabilization of $S_{2}$ when ammonia is bound. ${ }^{14}$

In conclusion, we have used mutagenesis, EPR spectroscopy, and $\mathrm{QM} / \mathrm{MM}$ calculations to provide the first structural model of the secondary ammonia-binding site in the outer coordination sphere of the OEC. Ammonia competes with D1-D61 as a hydrogen bond acceptor to W1, and while its binding is competitive with chloride, ammonia and chloride do not bind at the same site.

\section{ASSOCIATED CONTENT}

\section{S Supporting Information}

The Supporting Information is available free of charge on the ACS Publications website at DOI: 10.1021/acs.biochem.6b00543.

Three figures showing EPR spectra, one figure showing the dependence of ammonia binding on the choice of cryoprotectant, one figure showing primary and secondary site energetics, and a PDB file with the QM/MM coordinates of the secondary ammonia-binding model (PDF)

\section{AUTHOR INFORMATION}

\section{Corresponding Author}

*E-mail: gary.brudvig@yale.edu. Phone: (203) 432-5202. Fax: (203) 432-6144.

\section{Funding}

The authors acknowledge support by the U.S. Department of Energy, Office of Science, Office of Basic Energy Sciences, Division of Chemical Sciences, Geosciences, and Biosciences, Photosynthetic Systems. Experimental work was funded by Grant DE-FG02-05ER15646 (G.W.B.), mutant construction was funded by Grant DE-FG02-10ER16191 (R.J.D.), and computational work was funded by Grant DESC0001423 (V.S.B.). We thank the National Energy Research Scientific Computing Center (NERSC) and Shanghai Jiao Tong University $\Pi$ High Performance Computation Center for generous computer time allocations.

\section{Notes}

The authors declare no competing financial interest.

\section{ACKNOWLEDGMENTS}

We thank Prof. Marilyn Gunner and Dr. Sahr Khan for helpful discussions.

\section{ABBREVIATIONS}

DM, $n$-dodecyl $\beta$-D-maltoside; EDTA, (ethylenedinitrilo)tetraacetic acid; EPR, electron paramagnetic resonance; FTIR, Fourier transform infrared; HEPES, 4-(2-hydroxyethyl)-1piperazineethanesulfonic acid; $\mathrm{kDa}$, kilodalton; MES, 2-(Nmorpholino)ethanesulfonic acid; NTA, nitrilotriacetic acid; OEC, oxygen-evolving complex; PSII, Photosystem II; QM/ $\mathrm{MM}$, quantum mechanics/molecular mechanics; $\mathrm{S}_{n}$, S state intermediate $(n=0-4)$; WT, wild type.

\section{REFERENCES}

(1) Blankenship, R. E. (2014) Molecular Mechanisms of Photosynthesis, 2nd ed., Wiley-Blackwell: Oxford, U.K.

(2) Umena, Y., Kawakami, K., Shen, J.-R, and Kamiya, N. (2011) Crystal structure of oxygen-evolving photosystem II at a resolution of 1.9A. Nature 473, 55-60. 
(3) Kok, B., Forbush, B., and McGloin, M. (1970) Cooperation of charges in photosynthetic $\mathrm{O}_{2}$ evolution-I. A linear four step mechanism. Photochem. Photobiol. 11, 457-475.

(4) Vinyard, D. J., Khan, S., and Brudvig, G. W. (2015) Photosynthetic water oxidation: binding and activation of substrate waters for $\mathrm{O}-\mathrm{O}$ bond formation. Faraday Discuss. 185, 37-50.

(5) Messinger, J. (2004) Evaluation of different mechanistic proposals for water oxidation in photosynthesis on the basis of $\mathrm{Mn}_{4} \mathrm{O}_{\mathrm{x}} \mathrm{Ca}$ structures for the catalytic site and spectroscopic data. Phys. Chem. Chem. Phys. 6, 4764-4771.

(6) Siegbahn, P. E. M. (2006) O-O bond formation in the $S_{4}$ state of the oxygen-evolving complex in Photosystem II. Chem. - Eur. J. 12, 9217-9227.

(7) Pecoraro, V. L., Baldwin, M. J., Caudle, M. T., Hsieh, W.-Y., and Law, N. A. (1998) A proposal for water oxidation in photosystem II. Pure Appl. Chem. 70, 925-929.

(8) Brudvig, G. W. (2008) Water oxidation chemistry of photosystem II. Philos. Trans. R. Soc., B 363, 1211-1219.

(9) Szalai, V. A., Stone, D. A., and Brudvig, G. W. (1998) A structural and mechanistic model of the $\mathrm{O}_{2}$-evolving complex of Photosystem II. In Photosynthesis: Mechanism and effects (Garab, G., Ed.) pp 1403-1406, Kluwer Academic, Dordrecht, The Netherlands.

(10) Askerka, M., Vinyard, D. J., Brudvig, G. W., and Batista, V. S. (2015) $\mathrm{NH}_{3}$ Binding to the $\mathrm{S}_{2}$ State of the $\mathrm{O}_{2}$-Evolving Complex of Photosystem II: Analogue to $\mathrm{H}_{2} \mathrm{O}$ Binding during the $\mathrm{S}_{2} \rightarrow \mathrm{S}_{3}$ Transition. Biochemistry 54, 5783-5786.

(11) Sandusky, P. O., and Yocum, C. F. (1984) The chloride requirement for photosynthetic oxygen evolution: Analysis of the effects of chloride and other anions on amine inhibition of the oxygen-evolving complex. Biochim. Biophys. Acta, Bioenerg. 766, 603-611.

(12) Oyala, P. H., Stich, T. A., Debus, R. J., and Britt, R. D. (2015) Ammonia binds to the dangler manganese of the Photosystem II oxygen-evolving complex. J. Am. Chem. Soc. 137, 8829-8837.

(13) Pérez Navarro, M., Ames, W. M., Nilsson, H., Lohmiller, T., Pantazis, D. A., Rapatskiy, L., Nowaczyk, M. M., Neese, F., Boussac, A., Messinger, J., Lubitz, W., and Cox, N. (2013) Ammonia binding to the oxygen-evolving complex of photosystem II identifies the solventexchangeable oxygen bridge ( $\mu$-oxo) of the manganese tetramer. Proc. Natl. Acad. Sci. U. S. A. 110, 15561-15566.

(14) Vinyard, D. J., and Brudvig, G. W. (2015) Insights into substrate binding to the oxygen-evolving complex of Photosystem II from ammonia inhibition studies. Biochemistry 54, 622-628.

(15) Beck, W. F., de Paula, J. C., and Brudvig, G. W. (1986) Ammonia binds to the manganese site of the oxygen-evolving complex of photosystem II in the $S_{2}$ state. J. Am. Chem. Soc. 108, 4018-4022.

(16) Retegan, M., Krewald, V., Mamedov, F., Neese, F., Lubitz, W., Cox, N., and Pantazis, D. A. (2016) A five-coordinate Mn(IV) intermediate in biological water oxidation: spectroscopic signature and a pivot mechanism for water binding. Chem. Sci. 7, 72-84.

(17) Vogt, L., Vinyard, D. J., Khan, S., and Brudvig, G. W. (2015) Oxygen-evolving complex of Photosystem II: An analysis of secondshell residues and hydrogen-bonding networks. Curr. Opin. Chem. Biol. $25,152-158$.

(18) Sandusky, P. O., and Yocum, C. F. (1986) The chloride requirement for photosynthetic oxygen evolution: Factors affecting nucleophilic displacement of chloride from the oxygen-evolving complex. Biochim. Biophys. Acta, Bioenerg. 849, 85-93.

(19) Beck, W. F., and Brudvig, G. W. (1986) Binding of amines to the oxygen-evolving center of photosystem II. Biochemistry 25, 6479-6486.

(20) Pokhrel, R., Service, R. J., Debus, R. J., and Brudvig, G. W. (2013) Mutation of lysine 317 in the D2 subunit of Photosystem II alters chloride binding and proton transport. Biochemistry 52, 4758-4773.

(21) Pokhrel, R., McConnell, I. L., and Brudvig, G. W. (2011) Chloride regulation of enzyme turnover: Application to the role of chloride in Photosystem II. Biochemistry 50, 2725-2734.

(22) Pokhrel, R., and Brudvig, G. W. (2014) Oxygen-evolving complex of photosystem II: correlating structure with spectroscopy. Phys. Chem. Chem. Phys. 16, 11812-11821.
(23) Debus, R. J., Campbell, K. A., Gregor, W., Li, Z.-L., Burnap, R. L., and Britt, R. D. (2001) Does histidine 332 of the D1 polypeptide ligate the manganese cluster in Photosystem II? An electron spin echo envelope modulation study. Biochemistry 40, 3690-3699.

(24) Chu, H.-A., Nguyen, A. P., and Debus, R. J. (1994) Site-directed Photosystem II mutants with perturbed oxygen-evolving properties. 1. Instability or inefficient assembly of the manganese cluster in vivo. Biochemistry 33, 6137-6149.

(25) Boerner, R. J., Bixby, K. A., Nguyen, A. P., Noren, G. H., Debus, R J., and Barry, B. A. (1993) Removal of stable tyrosine radical $\mathrm{D}^{+}$affects the structure or redox properties of tyrosine $\mathrm{Z}$ in manganese-depleted photosystem II particles from Synechocystis 6803. J. Biol. Chem. 268, $1817-1823$.

(26) Brudvig, G. W., Casey, J. L., and Sauer, K. (1983) The effect of temperature on the formation and decay of the multiline EPR signal species associated with photosynthetic oxygen evolution. Biochim. Biophys. Acta, Bioenerg. 723, 366-371.

(27) Pal, R., Negre, C. F. A., Vogt, L., Pokhrel, R., Ertem, M. Z., Brudvig, G. W., and Batista, V. S. (2013) $S_{0}$-state model of the oxygenevolving complex of Photosystem II. Biochemistry 52, 7703-7706.

(28) Askerka, M., Vinyard, D. J., Wang, J., Brudvig, G. W., and Batista, V. S. (2015) Analysis of the Radiation-Damage-Free X-ray Structure of Photosystem II in Light of EXAFS and QM/MM Data. Biochemistry 54, 1713-1716.

(29) Askerka, M., Wang, J., Brudvig, G. W., and Batista, V. S. (2014) Structural changes in the oxygen-evolving complex of Photosystem II induced by the $S_{1}$ to $S_{2}$ transition: a combined XRD and QM/MM study. Biochemistry 53, 6860-6862.

(30) Becke, A. D. (1988) Density-functional exchange-energy approximation with correct asymptotic behavior. Phys. Rev. A: At., Mol., Opt. Phys. 38, 3098-3100.

(31) Becke, A. D. (1993) Density-functional thermochemistry. III. The role of exact exchange. J. Chem. Phys. 98, 5648-5652.

(32) Hay, P. J., and Wadt, W. R. (1985) Ab initio effective core potentials for molecular calculations. Potentials for $\mathrm{K}$ to Au including the outermost core orbitals. J. Chem. Phys. 82, 299-310.

(33) Wadt, W. R., and Hay, P. J. (1985) Ab initio effective core potentials for molecular calculations. Potentials for main group elements Na to Bi. J. Chem. Phys. 82, 284-298.

(34) Hariharan, P. C., and Pople, J. A. (1973) The influence of polarization functions on molecular orbital hydrogenation energies. Theoret. Chim. Acta 28, 213-222.

(35) Case, D. A., Darden, T., Cheatham, T. E., III, Simmerling, C. L., Wang, J., Duke, R. E., Luo, R., Walker, R. C., Zhang, W., Merz, K. M., Roberts, B., Hayik, S., Roitberg, A., Seabra, G., Swails, J., Goetz, A. W., Kolossváry, I., Wong, K. F., Paesani, F., Vanicek, J., Wolf, R. M., Liu, J., Wu, X., Brozell, S. R., Steinbrecher, T., Gohlke, H., Cai, Q., Ye, X., Wang, J., Hsieh, M.-J., Cui, G., Roe, D. R., Mathews, D. H., Seetin, M. G., Salomon-Ferrer, R., Sagui, C., Babin, V., Luchko, T., Gusarov, S., Kovalenko, A., and Kollman, P. A. (2012) AMBER 12, University of California, San Francisco.

(36) Zimmermann, J. L., and Rutherford, A. W. (1986) Electron paramagnetic resonance properties of the $S_{2}$ state of the oxygen-evolving complex of photosystem II. Biochemistry 25, 4609-4615.

(37) Pantazis, D. A., Ames, W., Cox, N., Lubitz, W., and Neese, F. (2012) Two interconvertible structures that explain the spectroscopic properties of the oxygen-evolving complex of Photosystem II in the $\mathrm{S}_{2}$ state. Angew. Chem., Int. Ed. 51, 9935-9940.

(38) Tsuno, M., Suzuki, H., Kondo, T., Mino, H., and Noguchi, T. (2011) Interaction and inhibitory effect of ammonium cation in the oxygen evolving center of Photosytem II. Biochemistry 50, 2506-2514. 